Original Research Article

\title{
Evaluation of drug promotional brochures in a tertiary teaching hospital of Kannur, India
}

\author{
R. Ratheesh ${ }^{1 *}$, Bindu Mohandas ${ }^{2}$, Bhaskaran K. ${ }^{3}$
}

\begin{abstract}
${ }^{1}$ Department of Pharmacology, ${ }^{2}$ Department of Community Medicine, KMCT Medical College, Calicut, Kerala, India ${ }^{3}$ Department of Pharmacology, Kannur Medical College, Kannur, Kerala, India
\end{abstract}

Received: 26 April 2018 Accepted: 04 May 2018

*Correspondence to: Dr. R. Ratheesh,

Email: doctorratheesh@ gmail.com

Copyright: (C) the author(s), publisher and licensee Medip Academy. This is an openaccess article distributed under the terms of the Creative Commons Attribution NonCommercial License, which permits unrestricted noncommercial use, distribution, and reproduction in any medium, provided the original work is properly cited.

\begin{abstract}
Background: Pharmaceutical industries worldwide are heavily involved in aggressive drug promotions. WHO has framed guidelines for ethical drug promotion in 1988. The transparency of pharmaceutical advertisements is important because decision of the physician is likely to be influenced by the claims made by the pharmaceutical companies in the promotional drug brochures and pharmaceutical industries treat their marketing material as "educational material" for doctors. Authors did this study to analyze the information given on drug promotional brochures by the drug companies using ethical criteria of drug promotion by WHO 1988 and to verify the authenticity of the claims given by the pharmaceutical companies in drug promotional brochures.

Methods: Cross sectional study extending from 1/8/2012 to 31/7/2013. $612 \mathrm{drug}$ promotional brochures satisfied our inclusion criteria. Drug brochures were analyzed with WHO ethical criteria 1988 and further categorizing the data into type of claims, number and source of references. Validity of journal articles were checked by using a validity measure developed by Cardarelli.

Results: Total 612 brochures satisfied inclusion criteria. INN was mentioned in $93.8 \%$ of collected brochures. Brand name was mentioned in $100 \%$ brochures. Content of active ingredients was mentioned in $92 \%$ of brochures. Name of the other ingredients known to cause problem $28.4 \%$ of brochures. Dosage form or regimen was mentioned in $23.2 \%$ of brochures. Approved therapeutic use mentioned in $65.7 \%$ brochures. Side effects and major adverse drug reactions were mentioned in $31.4 \%$ brochures. Precautions and contraindications and warnings were mentioned in $30.4 \%$ drug promotional brochures. Drug interactions were mentioned in $26.5 \%$ brochures. Name and address was mentioned by $69.1 \%$ brochures. There were 1144 claims and 739 references. Efficacy claims were $84.88 \%$ of the total claims. Main source of reference was from journal articles $(74.1 \%)$ and among them $49.65 \%$ were randomized control trials. Only $47.94 \%$ of the journal references were valid.

Conclusions: Brochures were lacking in vital information which included contraindication, warning, precaution, name of the other ingredients known to cause problem hence companies were found violating WHO ethical criteria. Claims were not well supported with references. Less than half of the given journal references were only valid. This study highlights the need of healthcare professionals to remain cautious about promotional material presented by pharmaceutical representatives.
\end{abstract}

Keywords: Brochures, Drug promotion, WHO criteria

\section{INTRODUCTION}

Medicines can play a crucial role in the attainment or maintenance of health, but it is vital that they are prescribed rationally. Doctors play a key role in ensuring 
that medicines are used appropriately. However, in recent years, growing concern has focused attention on the relationship between health-care professionals and the pharmaceutical industry - particularly the industry's influence on prescribing and dispensing decisions through a range of promotional tools, which can influence treatment choices. Pharmaceutical industries worldwide are heavily involved in aggressive drug promotions. ${ }^{1}$

New drugs in health care system are prescribed to the patients through doctors and the availability is of little value unless the prescribing doctor is aware of its existence and has important scientific information to effectively use it. ${ }^{2}$ Promotional product literature is more selective. It is disseminated through a controlled means and has got a targeted audience. The initial readership is $100 \%$. $^{3}$

A study conducted in Boston school of public health shows that in United States $81 \%$ more people in their marketing department than research and development department. ${ }^{4}$ Most continuing medical education activities are primarily supported by drug companies who often use this opportunity to influence the prescribing habits of doctors. These activities are paid for from the advertising budgets of these corporations. ${ }^{5,6}$

A recent study conducted by the Planning Commission's high-level expert group (HLEG) said the pharmaceutical industry spent more than $25 \%$ of its annual turnover on sales promotion alone as compared to $7 \%$ on research and development in 2008-09. Drug companies were recently caught red-handed writing scientific recommendations of their own products and submitting them to the Drug Controller General of India (DCGI) after getting them endorsed by top doctors for quicker marketing approval. Usually, scientific recommendations are submitted by experts after they have studied a drug's content. The endorsement is considered a crucial testimony that convinces the DCGI to trust the drug's effectiveness, in turn, allowing it to be launched in the market. ${ }^{7}$

WHO has framed guidelines for ethical drug promotion. Even Food and Drug Administration has code of conduct governing the control of drug promotional brochure. It is up to the pharmaceutical industry to follow the code of ethics. Following the code of conduct is one of the conditions of membership for manufactures association. Currently there are many code of practices out of which the important ones are International Pharmaceutical Association code of 2012 and Indian Pharmaceutical Associations code 2012 and WHO ethical criteria1988. ${ }^{8-10}$

WHO defines drug promotion as "all informational and persuasive activities by manufacturers and distributors, the effect of which is to induce the prescription, supply, purchase and/or use of medicinal drugs." Pharmaceutical companies have several ways of drug promotion which include leave behind leaflets, emails and drug promotional brochure. ${ }^{10}$ The transparency of pharmaceutical advertisements is important because decision of the physician is likely to be influenced by the claims made by the pharmaceutical companies in the promotional drug brochures and pharmaceutical industry treat their marketing material as "educational material" for doctors. ${ }^{11-14}$ Many studies have shown that drug advertisements are inconsistent with the code of ethics. But, very few studies have been conducted in India. ${ }^{15-17} \mathrm{It}$ is of utmost of importance to analyze the promotional material of the drugs in step with the growing popularity of evidence-based medicine. ${ }^{18,19}$ Hence with this background authors undertook this study to evaluate the drug promotional brochures in a tertiary teaching hospital in Kannur.

\section{METHODS}

The present cross sectional study was carried out in Kannur Medical College and Hospital from 1.8.2012 to 31.7.2013. The study was carried out after the approval of Institutional Ethical Committee of Kannur Medical College. All allopathic drug promotional brochures were collected from various outpatient departments of Kannur medical college hospital. Brochures containing ayurvedic preparations, brochures for medical devices, single brochures promoting more than two brands, reminder advertisements, repeat brochures, drug brochures promoting more than two brands on a single brochure were excluded. Reminder advertisements do not represent any therapeutic information and has different criteria for evaluation. Prior to the commencement of study Heads' of all the clinical departments in the hospital were approached and the type of study was explained to them and verbal consent to conduct the study was taken. All the department heads were requested to preserve whatever drug promotional brochure were presented to them by the medical representatives. Every day at 4pm except Sunday, drug promotional brochures presented to the consultants were collected from the respective department. Among the collected brochures satisfying inclusion criteria were kept and analyzed. Further the brochures collected daily were entered in the semi structured self-validated profoma having WHO ethical criteria 1988 and validity score of Robert Cardarelli. As per WHO ethical criteria for drug promotion authors analysed all the collected drug promotional brochures for its authenticity and retrivability. The International Nonproprietary Name (INN) component of the WHO ethical criteria of drug promotion was verified using the published list of INN available from the Controller General of patents, designs and trade mark. Further the brochures were analyzed for brand name whether it was mentioned or not, and the content of active ingredient(s) per dosage form or regimen. The other points evaluated included name of other ingredients known to cause problems, approved therapeutic uses, dosage form or regimen, side effects and major adverse medicine reactions, precautions, contraindications and warnings, major interactions, name and address of manufacturer or distributor, reference to scientific literature as appropriate. 
Claims if any were further categorised into the types of claims. A claim was defined as, any statement in drug promotional brochure concerning the safety or efficacy of a drug and other statements related to drug, patient or therapy presented with or with out references. Further number of claims were noted down. Each claim was categorised into various types according to the nature of claim observed which included claims on cost, efficacy, safety, pharmacokinetic property, pharmaceutical property, and emotional claims. References in support of the claims were categorised into type of reference i.e, if the reference is quoted from a journal then source of reference is categorised as journal likewise into books, websites, data on file and others. Journal article was categorised into the type of scientific literature in it which included randomised control studies, meta analysis etc. Validity of the given journal references was checked using a validity score developed by Roberto Cardarelli et al. The reference in the drug promotional brochure was considered valid if it satisfied 3 out of 3 major criteria and at least 2 out of 3 minor criteria. Data analysis was done by using SPSS version 20. Results were expressed in numbers and percentages.

\section{RESULTS}

A total of 612 distinct drug promotional brochures were obtained from 1008 drug promotional brochures which were collected during our study period. In these brochures $67.8 \%$ were single dosage forms and $32.2 \%$ were fixed drug combinations. Out of the 612 brochures collected during our study period $180(29.5 \%)$ comprised of chemotherapeutic drugs, followed by 86 (14.1\%) non steroidal anti inflammatory drugs, 67 (10.9\%) cardiovascular system, $55(9 \%)$ central nervous system, 54 $(8.8 \%)$ skin, $49(8 \%)$ respiratorysystem, $32 \quad(5.2 \%)$ gastrointestinal system, $20(3.3 \%)$ antihistamines, 18 (2.9\%) hormonal, 18 (2.9\%) ocular drug, 14 (2.3\%) blood, anaesthetic drugs $7(1.1 \%)$ and others consisting of nutritional supplements $12(2 \%)$.

The 612 drug promotional brochures collected were analysed with the WHO ethical criteria 1988. The results are shown in Table 1.

Out of 612 brochures, $73.52 \%$ were having claims. There were a total of 1144 claims in the analyzed drug promotional brochures out of which $84.88 \%$ claims on efficacy of drugs, followed by $42 \%$ regarding extra emotional claims, $33.55 \%$ on safety of the drug, $31.11 \%$ claims on convenience, $25.7 \%$ claims on pharmaceutical property, $22 \%$ on pharmacokinetic claims, $14.88 \%$ claims on cost.

Authors observed maximum number of two claims per brochure contributing to $25 \%$ of total drug promotional brochures analyzed. Brochures having one claim per brochure contributed to $12.3 \%$ in this study. $18 \%$ of the brochures in this study were having 3 claims per brochure. $10.21 \%$ of the brochures in this study were having 4 claims. $6 \%$ of the brochures in this study were having 5 claims per brochure. $2.1 \%$ of the brochures in this study were having 6 claims per brochure. Only $0.1 \%$ of the brochures in this study were having 7 claims per brochure.

Table 1: Analysis of drug promotional brochures with WHO ethical criteria.

\begin{tabular}{|lll|}
\hline Criteria & $\begin{array}{l}\text { Brochures } \\
\text { fulfilling } \\
\text { criteria (n=612) }\end{array}$ & Percentage \\
\hline $\begin{array}{l}\text { International non } \\
\text { proprietary name }\end{array}$ & 574 & 93.8 \\
\hline Brand name & 612 & 100 \\
\hline $\begin{array}{l}\text { Content of active } \\
\text { ingredient }\end{array}$ & 563 & 92 \\
\hline $\begin{array}{l}\text { Other ingredients } \\
\text { known to cause } \\
\text { problem }\end{array}$ & 438 & 71.6 \\
\hline $\begin{array}{l}\text { Dosage form or } \\
\text { regimen }\end{array}$ & 470 & 76.8 \\
\hline $\begin{array}{l}\text { Approved } \\
\text { therapeutic uses }\end{array}$ & 402 & 65.7 \\
\hline $\begin{array}{l}\text { Side effects and } \\
\text { major adverse drug } \\
\text { reactions }\end{array}$ & 420 & 68.6 \\
\hline $\begin{array}{l}\text { Precautions, } \\
\text { contraindications } \\
\text { and warnings }\end{array}$ & 186 & 69.1 \\
\hline Interactions & 162 & 26.5 \\
\hline $\begin{array}{l}\text { Name and address } \\
\text { of manufacturer/ } \\
\text { distributor }\end{array}$ & 423 & \\
\hline
\end{tabular}

In this study authors observed that there were 739 references out of which $74.01 \%$ were from journals, $12.99 \%$ from websites, $8.11 \%$ were data on file, $0.81 \%$ reference from books and other sources were $4.05 \%$. The other sources included treatment guidelines $1.3 \%$, newspaper or magazine articles $2.1 \%$, and clinical trial data $1.1 \%$. Among the 739 references in the 612 drug promotional brochures, the type of study authors observed in the references were randomized control trial $49.65 \%$, observational studies $13.92 \%$, review articles $9.74 \%$, meta analysis $8.35 \%$, and others $9.97 \%$ which included correspondence, case reports and letters to editorial. Validity of the references of the journal article was analyzed using a scale developed by Robert Carderelli. Authors observed that $47.94 \%$ of the references in the journal articles were valid.

\section{DISCUSSION}

Companies spend nearly $35 \%$ of sales on marketing of drugs and spend only one third on research and development. ${ }^{6}$ Promotion is nothing but one of the tactful ways to push the drugs into the market. Drug marketing does affect prescription habits of doctors and hence increases the sale. Physicians agree to the fact that meeting 
with the medical representatives affect their prescribing behaviour. Inappropriate prescribing contributors will grave public health and increase health care costs of the community. ${ }^{6-10}$ In this study $93.8 \%$ of drug promotional brochures mentioned INN or generic name. Similar results also have been reported by Phoolgen et al, in Nepal found that $87.32 \%$ of drug promotion brochures mentioned INN name. ${ }^{15}$ Similarly Mali et al, in his study in Nagpur on 513 drug promotion brochures reported $95.9 \%$ of brochures to be containing INN or generic name. However there were some studies which reported lower number of INN or generic name. Vlassov et al, in their study on 207 drug promotional brochures in Russia found that, in $39 \%$ of brochures only were reporting INN or generic names. ${ }^{20,21}$

Brand name was mentioned in $100 \%$ of brochures which was the same observation as in Mali et al study conducted in Nagpur, Phoolgen et al, study conducted in Nepal and Kasyap et al, study conducted in Bangalore. ${ }^{15,17,21}$

Name of other ingredients known to cause problems was mentioned in $28.4 \%$ of drug promotional brochures in this study while other authors (Kasyap et al, study observed $12 \%$, Mali et al observed 1.9\%) have observed less percentage of brochures mentioned this criteria. Phoolgen et al observed none of the drug promotional brochures mentioned other ingredients known to cause problem in their literature. ${ }^{15,17,21}$

Regimen or drug dosage was mentioned in $76.8 \%$ of brochures in this study. This finding was bit lower when compared with the study of Phoolgen et al, Chirac et al, Khakhkhar et al where it was $83.10 \%, 87 \%, 84 \%$ respectively. ${ }^{14-16}$ But in the study by Mali et al only $32.2 \%$ of brochures mentioned drug dosage. ${ }^{21}$

Approved therapeutic use was mentioned in $65.7 \%$ of drug promotional brochures. The findings from other studies revealed that it was slightly more than our results. The study conducted by Mali et al in Nagpur government hospital observed that out of 513 total brochures collected only $86.3 \%$ of brochures had mentioned approved therapeutic use of the drugs. ${ }^{21}$ Similarly, in the study conducted by Phoolgen et al, in Nepal, out of 100 brochures collected from psychiatric outpatient department, $83.10 \%$ of brochures mentioned approved therapeutic usage. ${ }^{15}$

Side effects and major adverse drug reactions were mentioned in $31.4 \%$ of total drug promotional drug brochures collected in this study. Phoolgen et al, study showed that only $11.27 \%$, Mali et al, and by Khakhkhar et al, in Gujarat, showed $8 \%$ of drug promotional brochures had mentioned side effects and adverse effects in both the studies. ${ }^{15,16,21}$

In this study, $30.4 \%$ of the drug promotional brochures mentioned precautions; this percentage was less when compared to other studies. Khakhkhar et al, observed only $6 \%$, Kasyap et al, observed $11 \%$ and Vlassov et al, had observed of $11 \%$ of total promoted brochures mentioned precautions in their study. ${ }^{16,17,20}$ Major drug interactions were mentioned in $26.5 \%$ of the drug promotional brochures, which was more when compared to other studies. In the study by Phoolgen et al, and Vlassov et al, it was observed that only $8.45 \%$ of brochures mentioned major interactions. ${ }^{15,20} 69.1 \%$ of the drug brochures mentioned name and address of the manufacturer. But in the study by Mali et al, Phoolgen et al, and Khakhkhar et al, it was observed that $70.6 \%, 84.50 \%$ and $100 \%$ respectively mentioned the name and address of the manufacturer respectively. ${ }^{15,16,21}$

Out of 612 brochures, $73.52 \%$ of the brochures had claims out of which, $84.88 \%$ of the brochures had efficacy claims. This was similar to the study conducted by Mali et al in Nagpur, where they found $92 \%$ of brochures mentioning efficacy claims. $^{21}$

Safety claims were seen in $33.55 \%$ of the brochures studied. $42 \%$ of, $31.11 \%$ of, $25.7 \%$ of, $22 \%$ of and $14.88 \%$ of the brochures had extra emotional claims, claims on convenience, pharmaceutical property, pharmacokinetic property and costs respectively. The findings of our study was similar to study conducted in Nagpur, by Mali et al, where they observed $37.8 \%$ of claims on safety, $29.6 \%$ of on pharmaceutical property, $17.9 \%$ of on extra emotional claims, $17.7 \%$ of on cost effectiveness, $16.7 \%$ of on pharmacokinetic properties, $16.4 \%$ of on convenience. ${ }^{21}$

Pharmaceutical claims in this study were mentioning about authentic certification of manufacturing plant, GMP certification, various packaging characteristics or technologies of the drug production. These claims were not having any references. Claims were highlighted on the promoted brochures using maximum paper area and depriving the brochure of its therapeutic information. Cost effective claims in the drug promotional materials mentioned either in the price of the drug or compared its price with competitive brands. Pharmaceutical companies are very clever to make multiple claims in their drug promotional brochures. In this study $44.4 \%$ of the collected brochures were having references. A total of 1144 claims were made by 739 references, indicating paucity of references to the claims in the brochures studied.

\section{CONCLUSION}

From the study it is evident that promotional materials do not follow the WHO's Ethical Criteria for Medicinal Drug Promotion. Most claims in the brochures do highlight the selective part of information about the drug and frequency of misleading promotion is very much difficult to determine. This study highlights the need of health care professionals in Kerala to remain cautious about promotional materials presented by pharmaceutical representatives. Creating awareness to the consultant regarding the pitfalls in the information given in pharmaceutical drug promotional brochures and raising 
complaints against the irrational drug promotion can be done to improve the scenario.

Funding: No funding sources

Conflict of interest: None declared

Ethical approval: The study was approved by the Institutional Ethics Committee of Kannur Medical College, India

\section{REFERENCES}

1. Understanding and Responding to Pharmaceutical Promotion A Practical Guide First Edition Working Draft for Pilot Field Testing. World Health Organization/Health action International Collaborative Project. $1^{\text {st }}$ Edition; 2009:9-24.

2. Stimson GV. Information contained in drug advertisements. British Medical Journal. 1975;4:5089. Available at: http://www.ncbi.nlm.nih.gov/pmc/articles/PMC1675 598/pdf/brmedj01476-0032.pdf

3. Medhi P, Prakash A. Promotional product literature. Practical Manual of experimental and clinical pharmacology. Jaypee Brothers Medical Publishers(P) Ltd. 2010:342-345.

4. Drugs, doctors and dinners. How drug companies influence health in the developing world. London: Consumers International; 2007 Oct:5-32.

5. Sagar A, Socolar D. Drug industry marketing staff soars while research staffing stagnates-Report. Boston University School of Public Health; December 2001.

6. Mamdani B. Drug deals. Indian J Med Ethics [online]. Apr-Jun. 2005;191;2(2):14. Available at: URL:http://www.iime.in/132ss063.html.

7. Sinha K, Ghildiyal S. Govt may lift ban on pharma firm sponsored tours for doctors. TNN. 2012 Nov 1. Available at: http://articles.timesofindia.indiatimes.com/2012-1101/india/34856424_1_pharma-companies-pharmaindustry-pharmaceutical-industry

8. International Federation of Pharmaceutical Manufacturers and Associations. [Cited on 2013 Oct 9]. Available at: http://www.ifpma.org/ethics/ifpmacode-of-practice/ifpma-code-of-practice.html

9. OPPI code of pharmaceutical practices. Organization of Pharmaceutical Producers of India; 2012. Available at: http://www.indiaoppi.com/OPPI\%20Code $\% 20$ of $\% 20$ Pharmaceutical\%20Practices\%20\%20-\%202012.pdf

10. Ethical criteria for medicinal drug promotion. Geneva: WHO;1988. [Citedon 2013 Oct 9]. Available at: http://apps.who.int/medicinedocs/documents/whozip 08e/whozip08e.pdf

11. Shetty VV, Karve AV. Promotional literature: How do we critically appraise?. J Postgrad Med [serial online] 2008;54:217-21. Available at: http://www.jpgmonline.com/text.asp?2008/54/3/217/ 41807.

12. Bradley C. Factors which influence the decision whether or not to prescribe: the dilemma facing general practitioners. Br J Gen Pract. 1992;42:454-8.

13. Schumock GT, Walton SM, Park HY, Nutescu EA, Blackburn JC, Finley JM, Lewis RK. Factors that influence prescribing decisions. Ann Pharmacother. 2004;38:557-62.

14. Chirac P, Pikon A, Poinsignon Y, Vitry A. Drug Marketing in FrenchSpeaking African Countries. Social Science and Medicine. 1993;36:1541-3.

15. Phoolgen S, Kumar SA, Kumar JR. Evaluation of the rationality of psychotropic drug promotional literatures in Nepal. Journal of Drug Delivery and Therapeutics. 2012;2(6):6-8. Available at: http://jddtonline.info/index.php/jddt/article/download /308/180\%E2\%80\%8E

16. Khakhkhar T, Mehta M, Shah R, Sharma D. Evaluation of drug promotional literatures using WHO guidelines. J Pharm Negative Results. 2013;4:33-8.

17. Kasyap SJ, Srikanth, Niveditha. Evaluation of the rationality of drug promotional literature in a tertiary care hospital. World $\mathrm{J}$ of Phar and Pharmac Sci. 2(4):1950-62.

18. Greving JP, Denig P, Zeeuw D, Haaijer-Ruskamp FM. Claims in advertisements for antihypertensive drugs in a Dutch medical journal. J Hypertens. 2007;25:71322.

19. Lexchin J. Enforcement of codes governing pharmaceutical promotion: What happens when companies breach advertising guidelines? CMAJ 1997;156:351-6.

20. Vlassov V, Mansfield P, Lexchin J, Vlassova A. Do drug advertisements in Russian medical journals provide essential information for safe prescribing?. West J Med. 2001 June;174(6): 391-4.

21. Mali SN, Dudhgaonkar S, Bachewar NP. Evaluation of rationality of promotional drug literature using World Health Organization guidelines. Indian J Pharmacol. 2010 October;42(5):267-72.

Cite this article as: Ratheesh R, Mohandas B, Bhaskaran K. Evaluation of drug promotional brochures in a tertiary teaching hospital of Kannur, India. Int J Basic Clin Pharmacol 2018;7:1089-93. 